\title{
Sales and marketing automation in the post-Covid-19 scenario: value drivers in B2B relationships
}

\author{
Daniela Corsaro $^{1} \cdot$ Isabella Maggioni $^{2} \cdot$ Mirko Olivieri $^{1}$
}

Received: 18 January 2021 / Accepted: 7 May 2021 / Published online: 17 May 2021

(c) Società Italiana Marketing 2021

\begin{abstract}
Digital technologies automating marketing and sales activities are rapidly spreading. The adoption of Sales \& Marketing Automation (S\&MA) systems allows companies to improve their marketing campaigns, track their customers' journey and generate real-time insights to respond to customers more efficiently and effectively. The Covid-19 pandemic has further increased the importance of S\&MA as customers have massively shifted towards digital channels to interact with businesses and purchase products and services. In this paper, we investigate how S\&MA generates value for companies in the post-Covid-19 scenario, adopting the perspective of the buyer organization. Based on insights generated through a qualitative and quantitative research, we propose a conceptual model explaining the value drivers of S\&MA in terms of benefits and sacrifices. Our research highlights that a mere focus on the technological side of these platforms limits the assessment of value generation as it is crucial to also consider customer-centric, operational and integration-based value drivers. By segmenting the S\&MA value perceptions of different companies, this research also provides guidelines to develop, promote and implement S\&MA solutions for buyers and vendors operating in B2B.
\end{abstract}

Keywords B2B relationships · Covid-19 - Sales and marketing automation

Mirko Olivieri

mirko.olivieri4@studenti.iulm.it

Daniela Corsaro

daniela.corsaro@iulm.it

Isabella Maggioni

imaggioni@escp.eu

1 Department of Business, Law, Economics and Consumer Behavior, IULM University, Milan, Italy

2 Department of Marketing, ESCP Business School, Turin, Italy 


\section{Introduction}

Companies are increasingly acknowledging the importance of developing a relational approach in their marketing and sales activities. The diffusion of digital technologies has increased the multiple actors that companies interface with within the service ecosystem. Technological systems show high potential for nurturing relationships with different stakeholders in the ecosystem. Indeed, companies can benefit from the automation of repetitive tasks and the tracking of customer behavior. These two aspects are the driving forces for marketing strategies and result in growing sales and profitability (Ko \& Dennis, 2004; Thaichon et al., 2018). Among these technological systems, Sales and Marketing Automation (S\&MA) solutions are technologies used to improve the effectiveness of marketing operations through automated, customized and data analysis-based activities (Mero et al., 2020). S\&MA systems are becoming more and more relevant due to the complexity of contexts in which companies are competing. These solutions support activities such as customized communications, email marketing, social media marketing, lead management, CRM integration, and marketing analytics. Indeed, the aim of S\&MA is to embrace these marketing tools and to provide companies with an overall view of all activities and optimize the internal processes, as well as the control and the measurement of results (Järvinen \& Taiminen, 2016).

The S\&MA market is expanding and it is expected to grow in the upcoming years. In 2019 the size of the global S\&MA market was valued at \$ 4.06 billion and an annual growth of $9.8 \%$ is expected until 2027 (Grand View Research, 2020). This trend is also confirmed in Italy, where $72 \%$ of companies have declared that in the upcoming months they will invest in S\&MA (Dawson, 2020), despite only one in four companies currently has automated at least one sales process (Baig et al., 2020). Companies are increasingly introducing S\&MA solutions; the effectiveness of these systems also depends on the ability of companies to integrate digital and physical interactions while maintaining a fluid relational approach (Corsaro, 2018).

In this scenario of rapid diffusion of S\&MA systems, the Covid-19 pandemic has further boosted this trend: digital channels have in fact played a key role during the lockdown to maintain relationships with customers, generating an acceleration adopting digital technology (Baig et al., 2020). Customers today expect to be able to communicate with brands, evaluate and purchase products and services on digital platforms in new forms and modalities (Shi et al., 2020). For companies, S\&MA represents an opportunity to differentiate themselves, for example, through remote assistance or managing post-selling activities.

The academic literature in this area has focused mainly on four broad categories, i.e., the benefits of S\&MA (Holloway et al., 2013), the effects of S\&MA on the sales force (Avlonitis \& Panagopoulos, 2005), the reasons why S\&MA systems fail (Barker et al., 2009), and the antecedents of S\&MA used by the sales force, by demonstrating the ease of use and adaptability of these automation systems that contribute to the effectiveness of the sales configurators (Mahlamäki et al., 2020).

However, most studies in the area adopt only the supplier perspective, making it surprising that the literature is largely silent about the customer perspective on 
S\&MA (Mahlamäki et al., 2020). Furthermore, past contributions mostly discuss micro-aspects of S\&MA. This fails to include a more holistic and systemic view of the phenomenon, which is key due to the increasing complexity of relating with customers and stakeholders, the speed of change and the strong interlink between businesses and social contexts, which the pandemic has remarkably stressed. As a consequence, a too simplistic view of S\&MA is not useful to deeply understand the phenomenon, its determinant as well as the implications for managerial practice (Hartmann et al., 2018).

Hence, the aim of this paper is to explore how S\&MA generates value for companies in the post-Covid-19 scenario, adopting the perspective of the buyer organization. We seek to answer the following research question:

RQ. How does S\&MA generate value for companies in the post-Covid-19 scenario? What are S\&MA value drivers from a buyer's perspective?

By conducting research involving a qualitative and quantitative phase, we propose a framework that explains the value drivers of S\&MA from a buyer's perspective in terms of benefits and sacrifices including more levels of analysis, in order to get a broader and systemic view of the phenomenon under investigation. By zooming in and out from micro aspect to a more general one, we contribute to create a middle range theory for S\&MA, which increasingly seems to be the core of marketing and sales research (Hartmann et al., 2020). We also analyze how S\&MA generates value for different organizations by proposing a segmentation of S\&MA value configurations and identify four clusters of companies that derive value from S\&MA in different ways.

The paper is organized as follows. First, in Sect. 2, it offers a review of the literature on the topic of S\&MA considered as the theoretical background of the research. In Sect. 3 we present the qualitative-quantitative methodology adopted to address our research aim. The results of the study are presented in the Sect. 4 . In the last sections of the paper, findings are discussed, conclusions, managerial implications and limitations and directions for future research are provided.

\section{Literature review}

\subsection{Sales and marketing automation: the state of the art}

The term "marketing automation" was first coined by Little (2001) and the rationale for these systems was a lack of adequate models for businesses dealing with huge amounts of data automatically collected online. Thus, the primary goal of marketing automation systems was to react in an adaptive way to the choices of consumers in online environments. Specifically, Little (2001) proposes five levels of how marketing automation operates, which are: (1) data input; (2) real-time decision rules; (3) decision rule updates; (4) site management feedback; and (5) choice of strategy. According to Little's (2001) framework, firms should implement real-time decision rules that are calibrated using historical data and continuously update them with 
data collected online. The outputs of marketing automation are insights and feedback for companies and recommendations to adapt sales strategies.

Today, marketing automation is one of the most promising areas of marketing technology (Redding, 2015), and for this reason the marketing literature has provided several definitions to conceptualize this technology. For example, Burka and Kelly (2018) define marketing automation as technologies focusing on the definition, planning, segmentation and tracking of marketing campaigns, allowing the marketing and sales functions to cultivate leads with highly personalized content aimed at attracting and retaining customers. More generally, there are two perspectives regarding the definition of marketing automation (Mero et al., 2020). First, marketing automation is considered to be a tool used to automate marketing operations, being a computerized technology to support companies in the achievement of their business objectives performing specific tasks (Buttle \& Maklan, 2015; Heimbach et al., 2015). Other scholars define marketing automation as a strategic initiative with the potential to revolutionize organizational structures, processes and culture of conducting marketing activities (Järvinen \& Taiminen, 2016). As the functions of marketing automation are becoming more sophisticated, companies could gain deeper insights into customers through customer relationship management (CRM) systems which allows the integration of marketing and sales (Kotler et al., 2006; Wiersema, 2013).

However, literature is at times confusing when referring to CRM and S\&MA. For example, Sin et al. (2005) define CRM technology as the Internet technology implemented for specific purpose of the CRM. This technology allows companies "to formulate more appropriate marketing strategies and to execute specific marketing actions more efficiently and quickly by offering superior first-line support and the access of integrated access customer data" (Chang et al., 2010, p. 850). More specifically, CRM is deployed for the specific purpose of managing customer relationships (Jayachandran et al., 2005; Sin et al., 2005); while S\&MA is a "tool which allows companies to align marketing and sales system interfaces to improve and accelerate lead qualification processes [...], and to deliver more effective content marketing strategies and thereby improve lead follow-up practices" (Järvinen \& Taiminen, 2016, p. 165).

In other words, S\&MA is often associated in the literature with CRM systems (Heimbach, 2015) and could be confused with related fields such as database marketing, interactive marketing, e-marketing, one-to-one marketing (Montgomery \& Smith, 2009). Indeed, the S\&MA systems have some principles in common but show peculiarities and dimensions which justify independent studies (Dijkstra, 2008).

In a post-Covid-19 scenario, S\&MA is expected to further influence and reinvent businesses and relationship management as companies will need to review their marketing and sales strategies and contextualize them in the "new normal" stemming from the pandemic. Baig et al., (2020) states that in post-pandemic scenario digital channels will be taken into consideration not only for low-value products, but also for new purchases or recurring orders in B2B: $70 \%$ of decision makers are in fact open to the possibility of managing purchasing processes completely remotely for contracts up to $\$ 50,000$. In this scenario, S\&MA is expected to play a key role to 
facilitate business, starting with mapping the customer journey in social media and online, with the aim of leveraging new marketing trends rapidly evolving in the postpandemic scenario, such as the need for updated communications in real-time (Baig et al., 2020). For these reasons, it is expected that one of the effects generated by the Covid-19 pandemic will be the acceleration in the adoption of marketing automation (Forbes, 2020).

\subsection{The value of S\&MA in the literature}

To conceptualize the value generated by S\&MA, we draw on the research stream on relationship-value which distinguishes between benefits and sacrifices (Corsaro \& Snehota, 2010; Ulaga \& Eggert, 2006). The topic of relationship value has been extensively addressed in the academic literature and attracted considerable interest from researchers since the 1990s, when Holbrook (1999) introduced the concept of "value" as the fundamental basis for marketing activities. Ulaga and Eggert (2006) further expand the concept of value by introducing the construct of relationship value stemming from the research stream of business and service marketing. Since then, literature has extensively investigated the concept of value in the fields of marketing and sales. Specifically, with reference to S\&MA, Buttle and Stan (2015) outline a set of values that this technology is able to provide to companies: (1) greater marketing efficiency, thanks to higher cost control, (2) greater productivity resulting from the numerous campaigns which are implemented through multiple channels simultaneously, (3) more effective marketing through a closed cycle, (4) greater responsibility for marketing expenses, thanks to better data and analysis, (5) greater responsiveness with instant response to opportunities and involvement in real-time marketing, (6) advanced marketing intelligence with integrated reporting and analysis features, (7) better customer experience through personalized and relevant communications offered at the best times, and (8) greater customer engagement through emotional identification and the customers behavior when they experience personalized messages. Moreover, the application of marketing automation generates high-quality sales leads through behavioral targeting and content personalization (Järvinen \& Taiminen, 2016). Hosford (2012) empirically demonstrates the advantages of S\&MA in terms of aligning the sales and marketing departments. Indeed, S\&MA enables direct customer-facing sales activities and can help sales professionals in managing long-term relationships with customers, as well as identify their specific needs and consequently sales opportunities. Therefore, S\&MA allows companies to convert relevant data from consumers, analyze it and derive high-quality information to be applied in the development of their business strategies (Tanner et al., 2005). In addition, Wood (2015) argues that automation systems play a key role in enabling customers to extract enterprise content and create their own tailored experience. These systems also allow customers to obtain content in the format and at the time they desire. In other words, S\&MA increases marketers' access to the customer journey, giving them the ability to tailor future customer experiences. Indeed, as demonstrated by the Mahlamäki et al. (2020) model, the adaptability of 
the system and the quality of the information represent the drivers of effectiveness perceived by organizations.

Although the benefits of S\&MA are widely acknowledged by the literature, some scholars have focused their research on the reasons why these technologies are not implemented. Biegel (2009) highlights that these technologies have been prey to overly ambitious goals, at the time necessary to sell these solutions to companies and identified the need for IT skills that are often far from the background of marketing and sales professionals. The result, according to Biegel, "was a somewhat allergic reaction on the part of marketers to everything related to technology, in favor of creative freedom" (2009, p. 209). Furthermore, among the sacrifices that S\&MA adoption entails, authors, such as Murphy (2018) and Xu et al. (2002), point out the need to reorganize the internal governance of the company starting from a total review of business processes with implications for employees that often go beyond the simple automation platform adopted. The importance of people to achieve business success from implementation of S\&MA systems is also claimed by Lin et al., (2018), who demonstrated how the support of top management is essential to obtain sufficient budget and resources for a technology implementation project. Generally, the support of the internal staff and the effort to share a realistic project plan that mainly consists of aligning with supervisors and employees is a decisive element in the adoption process of S\&MA (Gheni et al., 2017). Hence, as human supervision in the marketing automation processes remains fundamental, it is essential to define a clear strategy and guide the system towards it. For example, valid marketing policies related to satisfying customer needs cannot be replaced by technological systems (Murphy, 2018). According to Mohagheghi and Jørgensen (2017) skilled personnel is indeed a challenge in software implementation projects for marketing and sales in enterprises, as the role of competent staff becomes key both in the pre-implementation phase and when the platform has been adopted.

Previous literature on S\&MA has mostly investigated single vertical aspects of the phenomenon. However, two gaps emerge from research. First, few studies have considered the buyer perspective, while the majority focuses on the provider/ vendor's view. Second, a broader perspective of S\&MA that considers benefits and sacrifices at multiple levels is missing. This perspective should also include a key issue in the literature nowadays, such as the role human-machine interaction (Ma \& Sun, 2020), a well as the importance of observing phenomena in an ecosystem view (Vargo \& Lusch, 2004).

\section{Methodology}

We adopted an exploratory approach involving a qualitative and quantitative phase to conceptualize the value generated by S\&MA. In the qualitative phase, we conducted semi-structured interviews with marketing and sales managers to understand how S\&MA generates value for companies in the post-Covid-19 scenario and identify key value drivers. Subsequently, we carried out a quantitative study involving an online survey of marketing, digital and sales professionals to understand the relevance of different value drivers across a variety of organizations and present a 
segmentation of value drivers to highlight alternative perceived value configurations of S\&MA applications. Each phase's methodology is presented in the below sub-sections.

\subsection{Qualitative phase}

25 semi-structured interviews were conducted with marketing and sales professionals operating in Italian companies across different sectors and offering either services or goods. Through purposeful sampling (Johnson, 2015) we identified and selected information-rich individuals to cover various industries and sectors (Table 1). Interviewees were selected based on having a key role in purchasing and/or using S\&MA systems. We explored common perceptions related to S\&MA applications to obtain a multifaceted perspective of the phenomenon and identify value drivers (Creswell $\&$ Creswell, 2018). Each interview included a series of open-ended questions (10

Table 1 Interviewee profiles

\begin{tabular}{|c|c|c|c|c|}
\hline \# & Job position & Gender & $\begin{array}{l}\text { Seniority (in } \\
\text { years) }\end{array}$ & Industry \\
\hline 1 & Customer experience manager & M & 7 & Healthcare \\
\hline 2 & Sales manager & M & 10 & Healthcare \\
\hline 3 & Marketing director & $\mathrm{F}$ & 15 & Luxury \\
\hline 4 & Digital marketing manager & M & 6 & Banking and finance \\
\hline 5 & Customer experience manager & $\mathrm{F}$ & 6 & Food \& beverage \\
\hline 6 & Marketing communication officer & $\mathrm{F}$ & 5 & Food and beverage \\
\hline 7 & Marketing director & M & 13 & Insurance and financial services \\
\hline 8 & Sales manager & M & 7 & Travel \\
\hline 9 & Marketing director & $\mathrm{F}$ & 14 & Banking and finance \\
\hline 10 & Sales manager & M & 5 & Healthcare \\
\hline 11 & Brand manager & $\mathrm{F}$ & 6 & Fashion \\
\hline 12 & Marketing director & $\mathrm{F}$ & 15 & Pharmaceutical \\
\hline 13 & Brand manager & M & 8 & Beauty \\
\hline 14 & Marketing specialist & $\mathrm{F}$ & 4 & Cloud computing \\
\hline 15 & Marketing director & M & 11 & Manufacturing production \\
\hline 16 & Marketing specialist & $\mathrm{F}$ & 3 & Luxury \\
\hline 17 & Digital marketing specialist & $\mathrm{F}$ & 4 & Banking and finance \\
\hline 18 & Digital marketing manager & M & 7 & Healthcare \\
\hline 19 & Sales manager & M & 8 & Sportwear \\
\hline 20 & Customer experience manager & $\mathrm{F}$ & 7 & Sportwear \\
\hline 21 & Marketing manager & M & 9 & Manufacturing production \\
\hline 22 & Marketing director & $\mathrm{F}$ & 12 & Food and beverage \\
\hline 23 & Sales manager & $\mathrm{F}$ & 6 & Travel \\
\hline 24 & Communication specialist & M & 5 & Food and beverage \\
\hline 25 & Digital communication manager & $\mathrm{F}$ & 8 & Banking and finance \\
\hline
\end{tabular}


main questions and 5 probing questions) and lasted between 40 and 60 min for a total of $20 \mathrm{~h}$ of audio recordings that were transcribed before proceeding with the analyses.

Data analysis was conducted through a systematic coding procedure across three stages: (1) open-coding, (2) axial coding, and (3) selective-coding (Strauss \& Corbin, 1998) to identify themes and S\&MA value drivers. We applied the constant comparison method, noting emerging themes while comparing them across transcripts to ensure consistency and identify commonalities and differences (Goulding, 2005). Each identified category was validated by multiple participants to assure its application beyond a specific organization or industry (Bendapudi \& Leone, 2002).

\subsection{Quantitative phase}

Data was collected through an online survey administered to professionals and managers operating in marketing, digital and sales $(n=200)$. Participants were invited to complete the survey during the Italian Covid-19 lockdown period (March and April 2020). The sample profile is presented in Table 2 . The questionnaire was developed based on the findings of the qualitative phase and included a series of multiplechoice questions about the different categories of S\&MA benefits and sacrifices identified ("Appendix" A). Participants were also asked to provide some firmographic information (number of employees, annual revenue figures, year-over-year revenue growth, industry) and demographic information (gender, age, job position, years in the job position).

Data was analyzed through univariate descriptive statistics to estimate the relevance of the drivers of value in the purchasing process of S\&MA. We then conducted a segmentation analysis using latent class analysis (LCA) and the Latent Gold 5.1 software to understand heterogeneous perceptions of S\&MA value drivers across segments (Vermunt \& Magidson, 2002). To identify the optimal model, we estimated subsequent models with 1 to 10 latent classes. We used the Bayesian Information Criterion (BIC) to compare relative model fit, while the obtained segment profiles were evaluated in terms of interpretability, over-extraction and class separation (Collins \& Lanza, 2010; Masyn, 2013). Eight index variables were computed by summing relevant variables to reflect the occurrence of each benefit and sacrifice category (customer-centric, integration-based, operational and productrelated). The index variables were subsequently standardized to rescale them and allow for comparison $($ mean $=0, s t d=1)$. The standardized variables were used as indicators in the latent class analysis model, while number of employees, annual revenue, and year-over-year revenue growth were entered as covariates.

\section{Findings}

We propose a conceptual framework of the dimensions that drive the creation of value through S\&MA in B2B relationships. In this analysis, we specifically consider the perspective of the buyer's organization and the effects on value generation 
Table 2 Sample profile

\begin{tabular}{|c|c|c|}
\hline \multirow[t]{10}{*}{ Industry } & Other services & $28 \%$ \\
\hline & Manufacturing & $21 \%$ \\
\hline & Retail & $13 \%$ \\
\hline & Insurance services & $10 \%$ \\
\hline & Consultancy & $7 \%$ \\
\hline & Telecommunications & $5 \%$ \\
\hline & Travel, tourism and hospitality & $4 \%$ \\
\hline & Entertainment and Sport & $3 \%$ \\
\hline & Health services & $2 \%$ \\
\hline & Other activities & $7 \%$ \\
\hline \multirow[t]{3}{*}{ Type of business } & Mainly B2B & $38 \%$ \\
\hline & Mainly B2C & $24 \%$ \\
\hline & Both B2B and B2C & $38 \%$ \\
\hline \multirow[t]{4}{*}{ Number of employees } & Less than 10 & $34 \%$ \\
\hline & $10-50$ & $11 \%$ \\
\hline & $51-250$ & $15 \%$ \\
\hline & $250+$ & $40 \%$ \\
\hline \multirow[t]{4}{*}{ Annual revenues (in Euros) } & Less than $2 \mathrm{M}$ & $39 \%$ \\
\hline & $2-10 \mathrm{M}$ & $15 \%$ \\
\hline & $10-50 \mathrm{M}$ & $13 \%$ \\
\hline & More than $50 \mathrm{M}$ & $33 \%$ \\
\hline
\end{tabular}

Demographics

\begin{tabular}{lll} 
Gender & Male & $59 \%$ \\
Age & Female & $41 \%$ \\
& $25-34$ & $27 \%$ \\
& $35-44$ & $37 \%$ \\
& $45-54$ & $24 \%$ \\
& $55-64$ & $10 \%$ \\
Job position & $65+$ & $2 \%$ \\
& Marketing director & $29 \%$ \\
& Marketing manager & $20 \%$ \\
& Digital marketing manager & $25 \%$ \\
& CEO & $15 \%$ \\
& Brand manager & $7 \%$ \\
& Sales manager & $7 \%$ \\
Years in the job position & Other & $7 \%$ \\
& Less than 1 year & $9 \%$ \\
& $1-3$ years & $17 \%$ \\
& $3-5$ years & $25 \%$ \\
& $5-7$ years & $13 \%$ \\
& More than 7 years & $36 \%$ \\
\hline \multirow{3}{*}{ (1) } &
\end{tabular}

Sample size: $n=200$ 
stemming from the introduction of S\&MA solutions. We classify benefits and sacrifices into four categories, i.e., customer-centric, integration-based, operational and product-related.

\subsection{Customer-centric benefits and sacrifices}

S\&MA allows companies to gain a deeper understanding of their customers and improves the quality of the relationships with them. We classify these benefits as customer-centric, which includes the development of long-lasting and stronger relationships with customers through tailored communications and promotions, customer data collection and insight generation, customer feedback and review collection, and post-sale service.

Marketing automation is key to enable real-time interactions with our customers.

(Customer Experience Manager, Healthcare)

S\&MA enables real-time interactions which improve the quality of the relationship with customers. $48 \%$ of the sample acknowledge that the implementation of S\&MA resulted in a long-lasting and stronger relationship with customers. S\&MA does not only improve lead generation but boosts the effectiveness of retention initiatives. Specifically, the Covid-19 pandemic has shifted the focus towards a digitaldriven relationship development process which highlights the central role of human connection in a virtual environment.

We are now trying to establish a human connection even within the digital channel.

(Sales Manager, Healthcare)

After Covid-19, it is clear that we cannot only aim at quick sales anymore.

(Marketing Director, Luxury)

Covid-19 has increased perceived uncertainty, so we need to invest more in actions that create trust.

(Sales Manager, Healthcare)

In this context, S\&MA can support the development of customer relationships by vehiculating personalized promotions and communications (65\%), collecting customer information (54\%), feedback and reviews (48\%) and providing customized post-sales service $(44 \%)$.

However, it also becomes apparent that a series of challenges arise from the implementation of S\&MA solutions with reference to the final customer. $55 \%$ of participants reported difficulties in obtaining real-time data to feed into S\&MA systems. This is specifically due to potential costs associated with data acquisition and data privacy.

Another potential sacrifice that was commonly discussed is the risk associated with the disintermediation of the selling process. In fact, $59 \%$ of the sample believe 
that customers are more autonomous in their purchase process and tend to buy without the support of salespeople. However, sometimes the implementation of chatbots and conversational AI does not live up to the promise as lacking in relationship building skills and emotional engagement that are fundamental in B2B settings.

We had to increase our investment in customer care because human relationships remain key, customers are not always happy with a chatbot.

(Customer Experience Manager, Healthcare)

On the other hand, S\&MA solutions could lead to overwhelmed customers (47\%), who end up receiving several communications and interaction requests, which are quite often not relevant to their current needs. This can potentially harm the relationship with final customers and result in them leaving the company.

The risk of marketing automation is to exceed in interacting with customers and stress them.

(Marketing Director, Banking and Finance)

\subsection{Integration-based benefits and sacrifices}

Participants commonly discussed how S\&MA brings benefits by increasing the level of integration both at intra and inter-organizational level and involving the entire service ecosystem.

Firstly, S\&MA allows better coordination among sales, marketing and customer service departments (64\%) increasing the level of collaboration among functions and supporting the development of joint initiatives based on shared KPIs.

We started setting joint KPIs for marketing and sales department to boost collaboration.

(Digital Marketing Manager, Banking and Finance)

$59 \%$ of the sample highlighted how S\&MA allows for a better integration of internal and external data which then leads to generating deeper insights about customers and increases the information shared within the service ecosystem (49\%).

Data integration is key to get a $360^{\circ}$ view of the customer.

(Customer Experience Manager, Food and Beverage)

S\&MA solutions also allow a deeper integration with data obtained through social media, improving the quality of the insights generated through business intelligence activities $(46 \%)$.

From an integration perspective, the main sacrifices associated with S\&MA are related to the opportunistic behaviour that significantly limits data integration (67\%). Opportunism can negatively affect the successful implementation of S\&MA solutions and harness the information sharing with external stakeholders.

If the partners do not share information, it is impossible to act in real-time.

(Brand Manager, Fashion) 
The integration of S\&MA solutions with existing company databases and platforms is an issue faced by several companies (43\% of the sample). In addition, $41 \%$ acknowledge that integration is often undermined by a lack of collaboration within and among departments, which increases both effort and costs associated to the S\&MA implementation.

Building relationships among marketing, sales, and customer service is costly because they are resistant.

(Marketing Director, Luxury)

We invest time in job rotation to explain and educate people to put themselves in the shoes of others.

(Digital Marketing Manager, Banking and Finance)

\subsection{Operational benefits and sacrifices}

Operational benefits are related to the achievement of greater efficiency of the marketing and sales activities through the reduction of costs, the generation of higher quality data (45\%) and additional opportunities to act based on real-time insights.

If you get the information at the exact moment you need it, you can adjust immediately your strategy. (Marketing Director, Luxury).

Dashboards allows us to obtain real-time reports on the effectiveness of our marketing campaigns. (Marketing Communication Officer, Food and Beverage).

$54 \%$ of the sample highlighted how S\&MA solutions allow for acting based on real-time insights which leads to general improvements in the efficiency of marketing and sales initiatives (48\%), reducing overall costs and improving profitability.

People do not often realize the effect that automation has on internal costs

(Customer Experience Manager, Healthcare).

The acceleration of the sales cycle was also identified as a key benefit by $48 \%$ of the sample. In a world where market dynamics are evolving at an extremely fast pace, S\&MA provides a way for companies to cope with this velocity, without compromising the quality of their relationships with customers.

From a sacrifice perspective, we found the investments in resources and skill development dedicated to S\&MA (36\%) and the difficulties of adapt to ever-evolving market dynamics (37\%) as most relevant.

We experience costs once people do not use data to drive their decisions.

(Marketing Director, Pharmaceutical)

Therefore S\&MA best solutions are perceived as those that require little or no additional investment to update and are immediately comprehensible by sales and marketing staff. 
We do not want to experience any costs in terms of time of our people just to update the technology: it has to be easy and immediate.

(Brand Manager, Beauty)

Another area that was commonly identified relates to the necessity of reviewing internal processes when a S\&MA solution is introduced (32\%).

\subsection{Product-related benefits and sacrifices}

The fourth category of S\&MA value drivers is product-related. These drivers capture the value associated with capabilities and features of S\&MA solutions. 86\% of participants highlighted how the opportunity to integrate the platform easily and flawlessly within the systems already in use in the company and the ease of use and implementation of the system are important value drivers that are considered when evaluating alternative S\&MA options.

We all take distance from a system that is complex, internally it can be technological and sophisticated, but it has to be easy for us to use.

(Marketing Director, Insurance and Financial services)

The platform functional completeness $(85 \%)$ is another important aspect that generates value for the buyer company and reduces the tediousness of managing and integrating several systems, as well as interacting with different S\&MA providers.

I do not want to interact with too many providers. The vendor is expected to integrate its offering upstream in order to offer a complete solution.

(Sales Manager, Travel)

Another value component is related to the availability of prompt and efficient technical support (84\%) which represent a key driver when choosing S\&MA solutions.

I need the technology to follow the change in the business, this is why assistance and technical support is key.

(Customer Experience Manager, Food and Beverage)

As for the product-related category, the major sacrifices concern the initial cost of S\&MA systems (76\%). Companies often perceive the investment in these systems as too high, particularly when considering solutions offered by top players in the industry.

The best solutions in the market are very expensive.

(Marketing Specialist, Cloud computing)

In addition, the costs for updating or adding new modules to the system are also perceived as a main constraint $(55 \%)$.

When you buy a platform, somehow the vendor pushes you to buy new modules that become essential for its complete functioning. You are a victim of upselling. 
(Marketing Director, Travel)

Participants also discussed the difficulties related to the complexity of the platform $(34 \%)$ which could result in not leveraging the system to its full potential.

Another aspect commonly identified was related to the structure and terms of S\&MA supply contracts, with $31 \%$ of the sample considering them at times too rigid and bonding with a provider.

When the contract with the vendor is long-term, I perceive high opportunity costs; I prefer to pay for using the technology.

(Digital Marketing Manager, Banking and Finance)

\subsection{S\&MA value-based segmentation}

Through latent class analysis we identified different segments that reflect different perceived value configurations of S\&MA applications. Customer-centric, integration-based, operational and product-based benefits and sacrifices were entered as indicator variables, while firmographics was included as covariates to describe segment profiles. The optimal model was determined based on the lowest BIC value (Collins \& Lanza, 2010) and included four segments. This solution showed strong class separation and posed no issues related to over-extraction, as the smallest segment accounts for $15 \%$ of the sample. Table 3 provides a summary of indicators and covariates.

Cluster 1 Cluster 1 includes $34 \%$ of the sample. Companies in this cluster perceive S\&MA to be primarily beneficial with reference to customer-centric and product-related benefits. At the same time, they identify these two areas as the most challenging for a successful implementation of S\&MA solutions. The companies in this cluster are small in size, $63 \%$ have less than 10 employees and $77 \%$ generated revenues of less than $2 \mathrm{M}$ Euros. However, these tend to be growing companies with $44 \%$ of them recording an increase in their year-over-year revenues.

Cluster $231 \%$ of the sample belongs to cluster 2. The introduction of S\&MA solutions in these companies generates value with reference to the product benefits and improvements from an operational perspective. Integration-based sacrifices are the most relevant followed by operational ones. These companies tend to be large in size and growing, $83 \%$ have more than 250 employees, $79 \%$ generate revenues of over $50 \mathrm{M}$ Euros and $62 \%$ recorded increasing revenues compared to the previous year.

Cluster 3 Companies in cluster 3 (20\% of the sample) derive benefits from S\&MA applications primarily in terms of increased integration of processes and functions within the organization, which results in higher operational benefits, improving the efficiency and effectiveness of the sales and marketing functions. The major challenges faced by these companies are still ascribed to the operational side followed by product-related sacrifices. The majority of these companies are medium-large in size $(68 \%$ have more than 31 employees, $70 \%$ generates revenue of more than $10 \mathrm{M}$ Euros) and showing strong growing trends (79\% increasing their revenue YoY). 
Table 3 Latent class analysis results

\begin{tabular}{|c|c|c|c|c|}
\hline & Cluster 1 & Cluster 2 & Cluster 3 & Cluster 4 \\
\hline Cluster size & $34 \%$ & $31 \%$ & $20 \%$ & $15 \%$ \\
\hline \multicolumn{5}{|l|}{ Indicator variables } \\
\hline \multicolumn{5}{|l|}{ Benefits } \\
\hline Customer - centric & 0.41 & -0.57 & 0.92 & -0.65 \\
\hline Integration-based & -0.05 & -0.08 & 1.26 & -1.12 \\
\hline Operational & -0.20 & 0.04 & 1.14 & -1.25 \\
\hline Product-based & 0.15 & 0.14 & 0.51 & -1.31 \\
\hline \multicolumn{5}{|l|}{ Sacrifices } \\
\hline Customer - centric & 0.06 & -0.01 & 0.08 & -0.11 \\
\hline Integration - based & -0.49 & 0.56 & -0.51 & 0.12 \\
\hline Operational & -0.14 & 0.20 & 0.37 & -0.66 \\
\hline Product - based & 0.25 & -0.18 & 0.22 & -0.51 \\
\hline \multicolumn{5}{|l|}{ Covariates } \\
\hline \multicolumn{5}{|l|}{ Number of employees } \\
\hline$<10$ & $63 \%$ & $0 \%$ & $10 \%$ & $78 \%$ \\
\hline $10-50$ & $12 \%$ & $3 \%$ & $23 \%$ & $12 \%$ \\
\hline $31-250$ & $14 \%$ & $14 \%$ & $19 \%$ & $2 \%$ \\
\hline$>250$ & $10 \%$ & $83 \%$ & $49 \%$ & $9 \%$ \\
\hline \multicolumn{5}{|l|}{ Annual revenues } \\
\hline$<2 \mathrm{M} €$ & $77 \%$ & $0 \%$ & $8 \%$ & $78 \%$ \\
\hline $2 \mathrm{M} €-10 \mathrm{M} €$ & $20 \%$ & $6 \%$ & $22 \%$ & $20 \%$ \\
\hline $10 \mathrm{M} €-50 \mathrm{M} €$ & $3 \%$ & $15 \%$ & $34 \%$ & $1 \%$ \\
\hline$>50 \mathrm{M} €$ & $0 \%$ & $79 \%$ & $36 \%$ & $1 \%$ \\
\hline \multicolumn{5}{|l|}{ YOY revenue growth } \\
\hline Decreased by over $5 \%$ & $7 \%$ & $9 \%$ & $3 \%$ & $18 \%$ \\
\hline Decreased by $5 \%$ & $11 \%$ & $8 \%$ & $4 \%$ & $10 \%$ \\
\hline Unchanged & $39 \%$ & $22 \%$ & $15 \%$ & $49 \%$ \\
\hline Increased by $5 \%$ & $22 \%$ & $24 \%$ & $44 \%$ & $6 \%$ \\
\hline Increased by over $5 \%$ & $22 \%$ & $38 \%$ & $35 \%$ & $17 \%$ \\
\hline \multicolumn{5}{|l|}{ Industry } \\
\hline Other Services & $24 \%$ & $30 \%$ & $22 \%$ & $35 \%$ \\
\hline Manufacturing & $26 \%$ & $20 \%$ & $27 \%$ & $3 \%$ \\
\hline Retail & $21 \%$ & $7 \%$ & $6 \%$ & $15 \%$ \\
\hline Insurance services & $15 \%$ & $2 \%$ & $18 \%$ & $7 \%$ \\
\hline Consultancy & $3 \%$ & $14 \%$ & $0 \%$ & $13 \%$ \\
\hline Telecommunications & $0 \%$ & $4 \%$ & $8 \%$ & $7 \%$ \\
\hline Travel, tourism and hospitality & $3 \%$ & $7 \%$ & $3 \%$ & $3 \%$ \\
\hline Entertainment and sport & $2 \%$ & $5 \%$ & $3 \%$ & $0 \%$ \\
\hline Health services & $2 \%$ & $0 \%$ & $4 \%$ & $4 \%$ \\
\hline Other activities & $4 \%$ & $11 \%$ & $9 \%$ & $13 \%$ \\
\hline
\end{tabular}

Sample size: $n=200$ 
Cluster 4 Cluster 4 members (15\% of the sample) face major challenges in introducing S\&MA solutions, mainly related to the integration of these systems. Customer-centric benefits are the most relevant for these companies, however the difficulties and sacrifices for implementing S\&MA tend to be higher. These companies are small with $78 \%$ having less than 10 employees and generating less than $2 \mathrm{M}$ Euros. $49 \%$ recorded no change in their YoY revenues, while $28 \%$ experienced a decrease.

\section{Discussion and conclusions}

In this study we developed a conceptual model which explains the value of S\&MA in business relationships. The framework is presented in Fig. 1.

Our findings show that S\&MA should be conceptualized as a multidimensional phenomenon, holistic and multi-actor process, in which the relational dimension is still key and not only in a customer-centric logic, but also with respect to the external ecosystem and the internal relationships (Hartmann et al., 2020; Järvinen \& Taiminen, 2016). Our study also shows that the role of S\&MA automation has become more central during the Covid-19 pandemic as this crisis has brought a renewed focus on relationships, either in a physical or digital context, as well as the need for higher integration to cope with uncertainty and complexity.

Given the systemic nature of S\&MA, a micro-perspective of analysis could be limited in explaining the phenomenon, especially in a Covid-19 scenario. Previous contributions have stressed the technological side and implications of S\&MA solutions. We analysed how S\&MA generates value by identifying four categories of value drivers articulated in benefits and sacrifices and assessing how S\&MA value is generated across different company types.

The major value driver of S\&MA is customer-centric and reflects the improvements and challenges faced by companies implementing these solutions with reference to their final customers and their relationship with them. Our findings enrich the contributions of Buttle and Stan (2015) and Wood (2015) by bridging the benefits of stronger relationships and higher personalization, with a post-sales perspective where the company obtains feedback and reviews which can be used to implement real-time actions and enhance post-sales service. S\&MA customer-centric value was identified as most relevant for growing small enterprises which point out

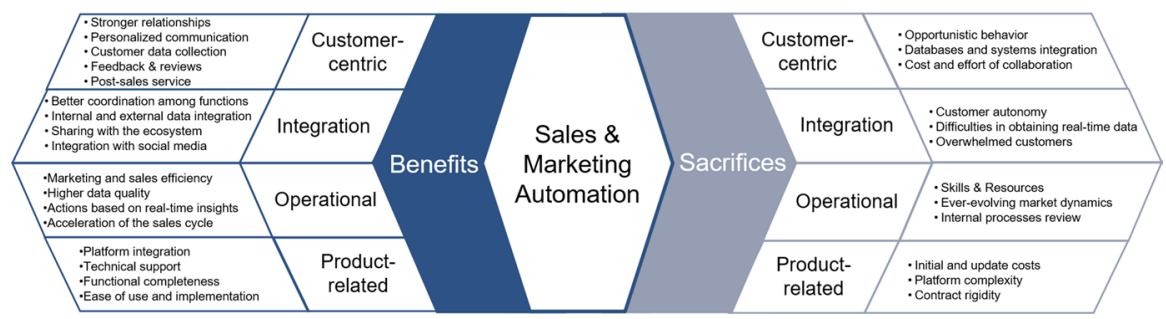

Fig. 1 Value drivers of S\&MA in B2B relationships 
how a balance is necessary as the implementation of S\&MA solutions has generated better-quality leads and long-lasting relationships based on data intelligence.

Integration-based value stems from a better alignment of companies' functions and systems and coordination within the service-ecosystem, while it is undermined by actors' opportunistic behaviour, perceived effort in collaborating and difficulties in platform integration. Our findings support Hosford (2012)'s insights that identify alignment as one of the major benefits achievable through automated marketing and sales systems. Furthermore, also the Le Meunier-FitzHugh and Piercy (2007) study argues that a solid collaboration between sales and marketing and conflict reduction of the two departments plays a key role for businesses. We extend this perspective to the broader service ecosystem discussing how S\&MA can generate value for multiple actors within and outside the company through a better alignment of their practices and data integration to fuel real-time actions. Integration-based benefits are particularly relevant for growing medium-large sized companies, while sacrifices associated with this area represent the main barrier for large companies.

From an operational perspective, the main benefits associated with S\&MA stem from the increased efficiency and effectiveness of sales and marketing activities, supporting Buttle and Stan (2015) and extending Tanner (2005)'s contribution. The acceleration of the sales cycle was identified as a major value driver allowing companies to close deals or drop low-value opportunities quicker, focusing on highvalue contacts and activities. However, S\&MA implementation requires continuous adaptation to the market dynamics, which in turn leads to frequent reviews of internal process. This, together with the need of skilled staff and the investment of resources, represents the main barrier to successfully introducing S\&MA solutions. Operational value drivers were perceived as most relevant by medium and large companies.

Our study introduces an additional category of value drivers referred to the S\&MA product. Specifically, large and medium sized companies highlight how the integration of the platform within their systems and databases is critical, while small enterprises value the ease of use and implementation the most. At the same time, the investment required for introducing and updating S\&MA systems is perceived as a major barrier.

Our findings corroborate the fact that an excessive focus on the mere technological side could result in a failure to implement S\&MA platforms, while a broader perspective including relational, operational and integrational factors should be considered.

In conclusion, this study contributes to the current debate on the implementation of S\&MA solutions in companies with a specific focus on the Covid-19 pandemic and its implications on marketing and sales management. We propose a framework comprising four value dimensions that identify and discuss the drivers of value generation of S\&MA solutions across different company types.

Our findings also contribute to the recent debate on sales transformation (Corsaro, 2018; Lacoste, 2018; Moncrief, 2017), where S\&MA is a key element having a transformative power only when combined with investments in human interactions and processes of integration and acceleration. 


\section{Managerial implications}

There are several implications of our study for managerial practice, the relevance of such implications is particularly high considering that there are several instances of unsuccessful S\&MA implementations. One reason ascribed to failure is that companies tend to purchase a new technology without a clear and extensive view of all benefits and sacrifices it can generate. This risk is particularly significant now as the pandemic has boosted an acceleration in the general adoption of technology.

Our study provides guidelines to buyers on the multiple elements they should consider in their investment decisions. These elements are not only related to the customer side, but also refer to the role other players could have in the ecosystem that may enable or limit the integration of data. At the same time, the benefits for internal employees derived from S\&MA are enormous. They include better returns from customers (especially for salespeople), but are also related to the opportunity to save time and free resources that can be invested in higher value activities, or simply increase their wellbeing.

However, our study shows that the implementation of S\&MA solutions can be often challenging with many hidden threads limiting its potential. In the past, these threads and costs were mainly linked to technological aspects, while this research emphases the relevance of human-related factors, such as the perception of opportunism and the risks associated with an un uncontrolled use of data. These elements are so important that if, until now, managerial practice has mostly used S\&MA as the enabler for the so called 'customer-centric approach', we could think about revising this idea into a 'human-centered approach' that better captures the ideas of multiple stakeholders which could be interested in the value of S\&MA.

On the other side, our study has shown implications are not only for customers who purchase S\&MA but for vendors too, by showing the presence of different clusters of companies which are characterized by different configurations of benefits and sacrifices, as well as toward addressing diversified sales and communications strategies around. For instance, when addressing small companies, vendors should stress the relational and product-related value generated by their solutions, while for medium and large companies a more attentive focus should be placed on the operational and integration-related benefits offered by the solution.

\section{Limitations and implications for future research}

As any research study, this one comes with some limitations in the interpretation of the results. By focusing on understanding how companies derive value from the implementation of S\&MA solutions, we refer to a specific context associated with the Covid-19 pandemic that has boosted the need of digital tools to develop and maintain relationships in a time of social distancing. This study is exploratory 
in nature and our data focus on the buyer organization that implements S\&MA systems. Future studies could extend this framework by analyzing and comparing different perspectives, including S\&MA providers (vendors), customers and final customers (consumers or companies). In addition, the proposed model could be further tested to understand the effect of different value drivers on outcome variables, such as relationship quality, profitability and actors' alignment within the service ecosystem. These limitations should be considered when interpreting and applying our results. Nevertheless, this study provides new insights for academics and practitioners alike.

\section{Appendix A}

Questionnaire: Benefits and sacrifices assessment.

What do you think are the main reasons for introducing marketing automation systems?

Generate new insights and intelligence.

Renew marketing and change our operational logic.

Personalize data-driven communication.

Increase business efficiency by reducing time.

Align the marketing function with sales.

Improve reporting and create shared dashboards.

Improve the customer experience.

Improve customer relationships.

Accelerate the sales cycle and increase lead conversion.

Improve the quality of available data.

Increased efficiency of the marketing function (time reduction).

Receive customer feedback and reviews.

Collect customer information / analyse customer behaviour.

Provide better post-selling services.

Reduce costs / improve marketing and sales efficiency.

Better integration of internal and external data to the company.

Respond to customer needs in real time.

Integrate our databases with social media.

What do you think are the main challenges or difficulties for the success of marketing automation systems in your company?

Market dynamics in continuous evolution.

Limited skills and dedicated resources within the teams.

Budget restrictions.

Problems of integration with business systems.

Internal organizational and process review problems.

Complexity of the platform.

Opportunistic behavior of stakeholders.

Greater customer autonomy and disintermediation of the sales process. 
Difficulty in collaboration and alignment of the various company functions.

Difficulty in obtaining insights and implementing actions in real time.

Risk of overwhelming customers with too many interactions and communications.

With reference to the marketing automation system as a product, which of the following aspects do you consider to be of greater value for the purpose of your purchase decision?

Functional completeness.

Easy to use.

Ease of implementation.

Reasonable purchase cost.

Reasonable upgrade cost.

Flexible contracts.

Technical support level.

Easy integration with the platforms used in the company.

Recommendations received.

Acknowledgements The authors thank the Editor of Italian Journal of Marketing Prof. Daniele Dalli and the two anonymous reviewers for their valuable feedback and comments. We also acknowledge the company Selligent for the collaboration in carrying out this research.

\section{Declarations}

Conflict of interest On behalf of all authors, the corresponding author states that there is no conflict of interest.

\section{References}

Avlonitis, G. J., \& Panagopoulos, N. G. (2005). Antecedents and consequences of CRM technology acceptance in the sales force. Industrial Marketing Management, 34(4), 355-368.

Baig, A., Hall, B., Jenkins, P., Lamarre, E., \& McCarthy, B. (2020). The Covid-19 recovery will be digital: A plan for the first 90 days. McKinsey. Retrived 25 April 2021, from, https:/www.mckin sey.com/business-functions/mckinsey-digital/our-insights/the-covid-19-recovery-will-be-digit al-a-plan-for-the-first-90-days\#

Baker, S. R., Bloom, N., Davis, S. J., Kost, K., Sammon, M., \& Viratyosin, T. (2020). The unprecedented stock market reaction to COVID-19. Working Paper. National Bureau of Economic Research. Retrived 3 January 2021, from.. https://www.nber.org/papers/w26945

Barker, R. M., Gohmann, S. F., Guan, J., \& Faulds, D. J. (2009). Why is my sales force automation system failing? Business Horizons, 52(3), 233-241.

Bendapudi, N., \& Leone, R. P. (2002). Managing business-to-business customer relationships following key contact employee turnover in a vendor firm. Journal of Marketing, 66(2), 83-101.

Biegel, B. (2009). The current view and outlook for the future of marketing automation. Journal of Direct, Data and Digital Marketing Practice, 10(3), 201-213.

Burka, K., \& Kelly B. (2018). Martech intelligence report: B2B marketing automation platforms: A marketer's guide, 6th edition. Third Door Media. martechtoday.com/new-b2b-marketing-automationplatforms- marketers-guide-updated-2018-212578 Accessed 3 January 2021martechtoday.com/ new-b2b-marketing-automation-platforms- marketers-guide-updated-2018-212578 Accessed 3 January 2021 
Buttle, F., \& Stan, M. (2015). Customer relationship management: concepts and technologies. (3rd ed.). Routledge.

Chang, W., Park, J. E., \& Chaiy, S. (2010). How does CRM technology transform into organizational performance? A mediating role of marketing capability. Journal of Business Research, 63(8), 849-855.

Collins, L. M., \& Lanza, S. T. (2010). Latent Class and Latent Transition Analysis: with Applications in the Social, Behavioral, and Health Sciences. John Wiley \& Sons.

Corsaro, D. (2018). Gestire la Sales Transformation. Franco Angeli.

Corsaro, D., \& Snehota, I. (2010). Searching for relationship value in business markets: are we missing something? Industrial Marketing Management, 39(6), 986-995.

Creswell, J. W., \& Creswell, J. D. (2018). Research Design: Qualitative, Quantitative, and Mixed Methods Approaches. (5th ed.). SAGE Publications.

Dawson, K. (2020). Selligent Cortex leverages multipurpose AI for its marketing cloud. Retrived 3 January 2021, from, https://www.selligent.com/resources/analyst-reports/selligent-cortex-leveragesmultipurpose-ai-for-its-marketing-cloud/ar451researchus

Dijkstra, A. (2008). The psychology of tailoring-ingredients in computer-tailored persuasion. Social and Personality Psychology Compass, 2(2), 765-784.

Forbes (2020). Why Companies Turn To Digital Marketing To Survive COVID-19. Retrived 13 January 2021, from, https://www.forbes.com/sites/bernardmarr/2020/03/20/why-companies-turn-to-digitalmarketing-to-survive-covid-19/?sh=783068242425

Gheni, A. Y., Jusoh, Y. Y., Jabar, M. A., \& Ali, N. M. (2017). The critical success factors (CSFs) for IT projects. Journal of Telecommunication, Electronic and Computer Engineering, 9(3-3), 13-17.

Goulding, C. (2005). Grounded theory, ethnography and phenomenology. A comparative analysis of three qualitative strategies for marketing research. European Journal of Marketing, 39(3/4), 294-308.

Grand View Research (2020). Marketing Automation Market Size, Share \& Trends Analysis Report By Solution (Email, Social Media), By Deployment (On-premise, Cloud), By Enterprise Size, By End Use, By Region, And Segment Forecasts. Retrived 3 January 2021, from https://www.grandviewr esearch.com/industry-analysis/marketing-automation-software-market

Hartmann, N. N., Wieland, H., Vargo, S. L., \& Ahearne, M. (2020). Advancing sales theory through a holistic view: how social structures frame selling. Journal of Personal Selling and Sales Management, 40(4), 221-226.

Heimbach, I., Kostyra, D. S., \& Hinz, O. (2015). Marketing automation. Business \& Information Systems Engineering, 57(2), 129-133.

Holbrook, M. B. (Ed.). (1999). Consumer value: a framework for analysis and research. Psychology Press.

Holloway, B. B., Deitz, G. D., \& Hansen, J. D. (2013). The benefits of sales force automation (SFA): an empirical examination of SFA usage on relationship quality and performance. Journal of Relationship Marketing, 12(4), 223-242.

Hosford, C. (2012). Automated marketing helps Jefferson National hone direct content. BtoB, 97(4).

Järvinen, J. (2016). The use of digital analytics for measuring and optimizing digital marketing performance. Academic dissertation, Jyväskylä Studies in Business and Economics, Jyväskylä.

Järvinen, J., \& Taiminen, H. (2016). Harnessing marketing automation for B2B content marketing. Industrial Marketing Management, 54, 164-175.

Jayachandran, S., Sharma, S., Kaufman, P., \& Raman, P. (2005). The role of relational information processes and technology use in customer relationship management. Journal of Marketing, 69(4), 177-192.

Johnson, J. S. (2015). Qualitative sales research: an exposition of grounded theory. Journal of Personal Selling \& Sales Management, 35(3), 262-273.

Ko, D. G., \& Dennis, A. R. (2004). Sales force automation and sales performance: Do experience and expertise matter? Journal of Personal Selling and Sales Management, 24(4), 311-322.

Kotler, P., Rackham, N., \& Krishnaswamy, S. (2006). Ending the war between sales and marketing. Harvard Business Review, 84(7/8), 68-78.

Lacoste, S. (2018). From selling to managing strategic customers-a competency analysis. Journal of Personal Selling and Sales Management, 38(1), 92-122.

Le Meunier-FitzHugh, K., \& Piercy, N. F. (2007). Does collaboration between sales and marketing affect business performance? Journal of Personal Selling and Sales Management, 27(3), 207-220.

Lin, A., Chang, T. H., Fu, H. P., Yeh, H. P., Hsu, K. Y., \& Tsai, H. Y. (2018). Analysis of the CSFs affecting project execution: A case application. Total Quality Management and Business Excellence, $29(7-8), 848-865$. 
Little, J.D. (2001). Marketing automation on the Internet. 5th Invitation Choice Symposium.

Ma, L., \& Sun, B. (2020). Machine learning and AI in marketing-Connecting computing power to human insights. International Journal of Research in Marketing, 37(3), 481-504.

Mahlamäki, T., Storbacka, K., Pylkkönen, S., \& Ojala, M. (2020). Adoption of digital sales force automation tools in supply chain: Customers' acceptance of sales configurators. Industrial Marketing Management, 91, 162-173.

Masyn, K. (2013). Latent class analysis and finite mixture modeling. In T. D. Little (Ed.), The oxford handbook of quantitative methods in psychology. (pp. 551-611). Oxford University Press.

McKinsey (2020). Identify and address the gaps creating barriers to automation. Retrived 13 January 2021, from, https://www.mckinsey.com/business-functions/mckinsey-digital/how-we-help-clients/ digital-2020/our-assessments/automation\#

Mero, J., Tarkiainen, A., \& Tobon, J. (2020). Effectual and causal reasoning in the adoption of marketing automation. Industrial Marketing Management, 86, 212-222.

Mohagheghi, P., \& Jørgensen, M. (2017). What contributes to the success of IT projects? An empirical study of IT projects in the Norwegian public sector. Journal of Software, 12(9), 751-759.

Moncrief, W. C. (2017). Are sales as we know it dying... or merely transforming? Journal of Personal Selling and Sales Management, 37(4), 271-279.

Montgomery, A. L., \& Smith, M. D. (2009). Prospects for personalization on the internet. Journal of Interactive Marketing, 23(2), 130-137.

Murphy, D. (2018). Silver bullet or millstone? A review of success factors for implementation of marketing automation. Cogent Business \& Management, 5(1), 1546416.

Redding, S. (2015). Can marketing automation be the glue that helps align sales and marketing? Journal of Direct, Data and Digital Marketing Practice, 16(4), 260-265.

Shi, S., Wang, Y., Chen, X., \& Zhang, Q. (2020). Conceptualization of omnichannel customer experience and its impact on shopping intention: A mixed-method approach. International Journal of Information Management, 50, 325-336.

Sin, L. Y. M., Tse, A. C. B., \& Yim, F. H. K. (2005). CRM: conceptualization and scale development. European Journal of Marketing, 39(11/12), 1264-1290.

Strauss, A.L., \& Corbin, J.M. (1998). Basics of Qualitative Research. SAGE Publications.

Tanner, J. F., Jr., Ahearne, M., Leigh, T. W., Mason, C. H., \& Moncrief, W. C. (2005). CRM in salesintensive organizations: A review and future directions. Journal of Personal Selling and Sales Management, 25(2), 169-180.

Thaichon, P., Surachartkumtonkun, J., Quach, S., Weaven, S., \& Palmatier, R. W. (2018). Hybrid sales structures in the age of e-commerce. Journal of Personal Selling and Sales Management, 38(3), 277-302.

Tuten, T. L. (2020). Social media marketing. SAGE Publications.

Ulaga, W., \& Eggert, A. (2006). Value-based differentiation in business relationships: Gaining and sustaining key supplier status. Journal of Marketing, 70(1), 119-136.

Vargo, S. L., \& Lusch, R. F. (2004). Evolving to a new dominant logic for marketing. Journal of Marketing, 68(1), 1-17.

Vermunt, J. K., \& Magidson, J. (2002). Latent class cluster analysis. In J. A. Hagenaars \& A. L. McCutcheon (Eds.), Applied latent class analysis. (pp. 89-106). Cambridge University Press.

Wiersema, F. (2013). The B2B agenda: The current state of B2B marketing and a look ahead. Industrial Marketing Management, 4(42), 470-488.

Wood, C. (2015). Marketing automation: Lessons learnt so far. Journal of Direct, Data and Digital Marketing Practice, 16(4), 251-254.

Xu, Y., Yen, D. C., Lin, B., \& Chou, D. C. (2002). Adopting customer relationship management technology. Industrial Management and Data Systems, 102(8), 442-452.

Publisher's Note Springer Nature remains neutral with regard to jurisdictional claims in published maps and institutional affiliations. 